\title{
The Role of Gender and Education on Small Business Performance in the South African Small Enterprise Sector
}

\author{
Dr Simon Radipere \\ Department of Business Management, University of South Africa, South Africa \\ radipns@unisa.ac.za \\ Dr Shepherd Dhliwayo \\ Department of Business Management University of Johannesburg, South Africa \\ sdhliwayo@uj.ac.za
}

\section{Doi:10.5901/mjss.2014.v5n9p104}

\begin{abstract}
The study aims to find out the extent to which demographic factors influence business performance. This study examined the effect demographic variables: gender and education of owner have on business performance. Business performance is measured by income, profit, market share, return on income or investment, number of employees and product line. A structured research instrument was used to collect data from 500 SMEs in retail industry through interviewer administrated and selfadministrated survey and $93 \%$ of questionnaires were returned. It was found that there is a significant difference between mean values of business performance and the demographic variables, gender and education. The results show that there is a significant difference in performance, among the different educational levels. Those with higher levels of education, such as diplomas and degrees should be encouraged to take up entrepreneurship as career options since the businesses they would run (according to the study's findings) will perform better and this would be good for the economy. The results also show that the variable "gender" does play a significant role in business performance. This implies that gender affects business performance.
\end{abstract}

Keywords: small business performance, education, gender and SMEs.

\section{Introduction}

Throughout the world, entrepreneurship is seen as the driving force in economic development with some authors arguing that it is a fundamentally value driven activity. Morris, Schindehutte and Lesser (2002) argued that personal values seemed to have important implications not only for the decision to pursue entrepreneurship but also the way the venture behaves or performs. Scholars in entrepreneurship have been searching for constructs of individual characteristics that are unique to entrepreneurs and how these affect business behaviour. The researchers will therefore investigate if values gender and education of owner has impact on operational performance.

A lot of attention has been devoted to the role of entrepreneurial values in successful entrepreneurial endeavours. Morris et al (2002) argued that entrepreneurial values reflect the entrepreneur's conscious view of himself or herself. Seminal work by McClelland (1998) and other African studies (Urban, 2004) conclude that psychological variables and race and ethnicity are important predictors of entrepreneurial activity

Other studies by (Mitchell, Busenitz, Morsem, Seawrignht, Perdo \& Kenzie, 2002) focused on entrepreneurial motives, values, beliefs and cognitions to examine relationship between these and national culture. The aim was to find out if the national culture was entrepreneurial or not and if this was dependant on the entrepreneurial variables. A better understanding of the motivations for business ownership can help policymakers design policies that encourage and promote the creation of businesses.

Besides understanding the business start-up factors, the researchers felt it necessary to find out if gender and education has an effect on how operating ventures perform. This is imperative in countries like South Africa which have Iow (Total Entrepreneurial Activity) TEA rate. The challenges in most developing countries is whether entrepreneurial and venture support should be given to woman (who experience the higher levels of unemployment) who relatively lack business skills. On the same vein, it becomes important to establish whether education or which education levels can result in better performing enterprises. 
The high failure rate of small businesses makes it necessary to further examine if demographic factors such as gender and education influence start-ups to succeed in business. The role of gender and education will be investigated to find out if these factors have any impact on business performance.

The study aims to examine the effect of gender and education of owner on business performance

The study is structured in the following manner. Section 1 presents the introduction of the study. Section 2 present the literature review which elaborates the constructs used in this study and proposes hypotheses for each construct to measure the impact of each to business performance. Then, section 3 present the research methodology of the study. Section 4 presents the analysis and findings of the study regarding the hypotheses proposed for each construct. Finally, section 5 concludes the paper with a discussion of the findings and suggests recommendations.

\section{Literature Review}

The literature will look at how the demographic variables; gender and education of owners impact on business performance of small entrepreneurs.

\subsection{Business performance}

Entrepreneurship scholars have attempted to explain performance by investigating the relationship between entrepreneurial orientation and firm performance (Lumpkin \& Dess 2001). Businesses with entrepreneurial orientation have the capability to discover and exploit new market opportunities (Wiklund \& Shepherd, 2003). Other research has employed a variety of financial measures like cash flow, return on assets and return on equity to assess firm performance. Some studies suggest a combination of financial and non-financial measures to offers more comprehensive evaluation on firm performance (Li, Huang \& Tsai 2009). Subjective non-financial measures include indicators such as perceived market share, perceived sales growth, customer satisfaction, loyalty and brand equity (Li et al, 2009). Murphy, Trailer and Hill (1996) examined 51 published entrepreneurial studies using performance as the dependent variable and found that the most commonly considered dimensions of performance were related to efficiency, growth and profit. Efficiency comprises some financial measures like return on investment and return on equity; growth focuses on increase in sales, employees or market share; and profit includes return on sales and net profit margin.

Performance of business results from consistency of structural and strategic factors and congruency of the structural and strategic factors with contextual factors. This means that for an organisation to be maximally effective, it must have configurations that are internally consistent and that fit multiple contextual dimensions (Wiklund \& Shepherd). Firms that are able to align certain firm attributes with the characteristics of the environment outperform other firms. Firms that fail to achieve such alignment will eventually be competed out. A failure to align to these elements will be detrimental to performance.

\subsection{Gender and small business performance}

Arenius and Minniti (2004) posited that factors influencing women entrepreneurship attributed to work status and socioeconomic factors. There is too much of gender differences in labour market especially for high-achieving job (Bengtsson, Sanandaji \& Johannesson, 2012). The controversial explanation for this disparity is that women have innate personality traits that are not compatible with competitive, challenging and risky work environment. Around the world, the rate of male entrepreneurs exceeds that of female, e.g. in USA, $14 \%$ of male against $8 \%$ of female and in Europe the corresponding figures are $19 \%$ and $10 \%$ respectively (Bengtsson et al, 2012).

The GEM (2010) reported that the ratio of male to female participation in entrepreneurial activity varies across the total sample of GEM countries, reflecting differences in culture and customs regarding female participation in the economy. The GEM (2009) reported that in South Africa, men are 1, 5 times more likely to be involved in entrepreneurial activity than women. The 2010 GEM Global Report indicates that for many Latin American countries (Argentina, Chile, Brazil and Peru), the gender gap in total entrepreneurial activity is low. In Brazil, women are more likely to be involved in TEA than men. The $2011 \mathrm{GEM}$, reported improvement of female involvement in entrepreneurship which shown a female entrepreneurs outnumbered male entrepreneurs by $53 \%$ to $47 \%$. The same GEM reported an improved and achieved TEA rates that are two to three times higher than that achieved by South Africa. For now, South Africa TEA rate shows an increase in female involvement between 2006 and 2011 of 43, 8\% which is still lower than increase in male involvement of $94.8 \%$.

It is important to understand the roots of this gender gap because entrepreneurship carries societal benefits; 
entrepreneurs innovate, introduce a product, create jobs and contribute to economic growth. Studying the reason for gender gap from academic perspective can yield new insights on how to encourage and support entrepreneurs.

This study build analysis on the seminal work of Schumpeter (1934) who said that individual who break new paths and undertake entrepreneurial ventures must have a special psyche.

Many factors undoubtedly contribute to disparity between men and women in entrepreneurial career interests and behaviours. Gender is well studied individual characteristic that is believed to have significant influence in entrepreneurial activities. Quan (2012) reported that males are more likely than women to have entrepreneurial intention, whether measured as deliberate intention or impulsive intention. He further reported that male intends to be more optimistic and more likely to take risks than females in general. Therefore the study look if gender impact on performance of business.

Rosa, Carter \& Hamilton (1996) reported that women perform less well on quantitative financial measures such as jobs created, sales turnover and profitability. They further argued that women do not enter business for financial gain but to pursue intrinsic goals (independence, flexibility to interface family and work commitments). Their study found that men were significantly more likely to than women to want to expand and they perform much better than women.

Studies by Cliff (1998), comparing the performance of male and female owned firms has consistently shown that businesses by women tend to be small than those headed by men, whether size, is measured by gross revenues, number of employees or profit level. Other study conducted in Norway found that male entrepreneurs were more likely to state positive growth intentions than female entrepreneurs.

The study therefore hypothesizes that (hypothesis 1): There is a significant difference between the performance of female and male owned small businesses $\left(\mathrm{H}_{0} \mathrm{1}\right)$.

\subsection{Education and business performance}

A healthy and educated workforce is vital to an organization's competitiveness and productivity. For a country to be competitive, it needs a sound basic education. According to 2010/2011 Global Competitive Report, South Africa continues to languish at the bottom end of the scale. GEM (2011) reported that South Africa's rates of education decreased between, 2006 to 2011 and this imply that even the rate of entrepreneurial activity also decreased. This is a concern as South Africa spends more (R189.5b) on education than any other African countries and closer to what is spent by wealthy OECD countries. A high quality of education and training is a pillar of productivity and competitiveness.

Takahashi (2009) further examined the relationship between human resources and performance. He points out that performance is the objective of the business and thus it is treated as the dependent variable. The independent variables are human resources variables at the beginning of the business such as education, and the previous experience of entrepreneurs. Human resources involve the productive services people provide to the business in the form of their skills, knowledge, expertise and decision-making capability for business.

The education of entrepreneurs can impact the path to business success because it is the process of building absorptive capacity of managers such as confidence, psychology, knowledge and skills. Takahashi (2009) indicates that one of the success factors in small business is the education level of the owner, which can assist the business to survive and manage a complex environment and keep business profitability.

The GEM (2010) reported that education increases an individuals' belief to start a business and also the possibility that the business will survive beyond start-up phase. It is therefore important to understand the educational levels of the owner managers. Many studies in literature show that education of workers about their work increases their performance. This increase in performance is reflected on the business performance. Education is the preconditions of building a successful enterprise resource planning.

Akar, Esen \& Ozer (2013) pointed out that the process of ensuring desired behavioural change of an individual is accepted to be the definition of education. Education that plays the basic role in the acceptance and use of information technologies increases knowledge and profession level. It is an integrated part of enterprise resource planning implementation and is one of the critical success factors. Failure in education causes implementation problems. To show that an education is successful, workers should be able to solve problems that they face in the system after education. Education is important to ensure an efficient use of the system, to benefit the company, to overcome difficulties in implementation and expanses. Education is accepted to be the key process in supporting of organisational development (Akar, Esen \& Ozer, 2013). Workers have to know what to do and how to do it in order to increase performance of an organisation and emphasized the importance of education.

This study therefore suggests that:

Hypotheses $2 \mathrm{H}_{0} 2$ : There is no statistical significant difference between the mean values of business performance and education of small business owners $\left(\mathrm{H}_{0} 2\right)$. 
Hypotheses $3 \mathrm{H}_{0} 3$ : There is no statistical significant difference between the mean values of business performance and different education levels (strata) $\left(\mathrm{H}_{0} 3\right)$.

\section{Methodology}

An ex post facto and cross sectional design was used in this study. The study assumes causality and statistical inferences about how the whole population will be made based on a representative sample.

The population of the study is SMEs (Small and Medium enterprises) in the retail sector of the Gauteng province of South Africa. The researcher uses the brabys.com populations of SMEs in Gauteng. This organisation is a reliable and leading registry of SMEs in the country. The population size of brabys.com is 10000 SMEs in the retail industry. The study population was therefore based on10 000 SMEs.

According to Cooper and Schindler (2008:409), the sample size that is acceptable is $5 \%$ of the total population. Given this study's estimate of a population of 10000 , it means that the targeted sample was 500 respondents (that is, 10 000 entrepreneurs $X 0.05=500$ respondents).

Probability sampling was used to ensure that each member of SME population is given a known non-zero chance of selection. Simple random sampling was utilised to identify the respondents. This increased accuracy and precision of the sample in representing the characteristics of the population of SMEs in retail industry in the province.

A structured research instrument (a questionnaire) was used to collect data through self-administrative interviews.

The questionnaire was designed to encompass three constructs gender and education of owner, and business performance

\subsection{Gender of business owner}

The question asked for the gender of the owner of the business. The choices were male, female and other. Other depicted a situation where the business was equally owned by people of both genders. Where a respondent indicated "other" they were requested to explain further.

\subsection{Education of owner}

A single question asking for the highest educational level of the business owner was asked. The choices availed are the following: grade 1-7; grade 8-12; diploma; degree and post graduate. Respondents were asked to choose the category in which their highest education level fell.

\subsection{Business Performance}

Murphy, Trailer and Hill (1996) examined 51 published entrepreneurial studies using performance as the dependent variable and found that the most commonly considered dimensions of performance were related to efficiency, growth and profit. Efficiency comprises some financial measures like return on investment and return on equity; growth focuses on increase in sales, employees or market share; and profit includes return on sales and net profit margin.

The respondents were required to state how their businesses performed in the past five years. The questions were aimed at finding out the extent to which businesses had performed in the following areas: income, profit, market share, return on investment, number of employees and product line. The business performance construct was measured through 6 questions covering each of the above areas and a five-point Likert scale (decreased significantly, decreased a bit, no change, increased a bit and increased significantly) was used for each of the six questions that was asked.

The assumption was that demographic variables gender and education would have an impact on performance of business as intimated in literature. The researcher therefore wanted to see if this was true and to find out which variable affected business performance and to what extent.

\section{Results and Discussion}

Results show that, $64 \%$ of the respondents were male and $35 \%$ were females. Educational levels were presented as follows: < grade 7 (3.6 \%); grade 8-12 (36\%); diploma (30\%); degree (23\%) and postgraduate (6\%). below.

The construct business performance is valid as shown by an eigenvalue larger than one as shown in Table 1 
The study's two hypotheses were measured using the Wilcoxon test (Kruskall-Wallis) method.

The method was adopted for use since there will be two independent variables to be tested. The ANOVA is used to test the main and the interaction effects of categorical variables on a continuous dependent variable, controlling for the effects of selected continuous variables which co-vary with the dependent.

The non-parametric Wilcoxon test (Kruskall-Wallis) was used because if the construct score is not normally distributed, then a non-parametric test is used. In this section the Kruskall-Wallis test is used (Diamantopoulos \& Schlegelmilch, 2002). The results of the two tests (hypotheses) are shown in table 1.

Table 1. Kruskal-Wallis test on business performance

\begin{tabular}{|l|c|c|c|}
\hline & Chi-Square & Df & Asymp. Sig. \\
\hline Gender & -2.294 & 4 & 0.022 \\
\hline Owner's education & 18.139 & 4 & 0.001 \\
\hline
\end{tabular}

Confidence interval: $95 \%$

$\mathrm{a}=0.05$

\subsection{Gender and business performance}

Null hypothesis $H_{0} 1$ : There is no statistical significance difference between the mean value of gender and the variable business performance.

Results show that there is a statistical significant difference between the mean value of gender and business performance $\left(\mathrm{H}_{0} 1\right)$ with the $\mathrm{p}$-value of $0.022,<0.05$ at a $95 \%$ confidence level.

Hypotheses Hol is rejected.

Hypothesis $\left(\mathrm{H}_{0} 1\right)$ is rejected since there is a significant difference between the means of the two variables. This result shows that the variable "gender" does play a significant role in business performance. This implies that gender affects business performance.

According to Van Scheers \& Radipere (2007), social norms are more likely to play a role in gender differences particularly since women traditionally have more domestic responsibilities (than males) to fulfil, such as managing the household. Quan (2012) reported that males are more likely than women to have entrepreneurial intention, whether measured as deliberate intention or impulsive intention. He further reported that male intends to be more optimistic and more likely to take risks than females in general. Studies by Cliff (1998), comparing the performance of male and female owned firms has consistently shown that businesses by women tend to be small than those headed by men, whether size, is measured by gross revenues, number of employees or profit level.

Research has to be conducted to find out why South African women do not perform as well as men in business.

\subsection{Owner's education and business performance}

Hypothesis $\mathrm{H}_{0} 2$ states that: There is no statistical significant difference between the mean value of education and business performance.

Results as appears in table 1 show that there is a statistical significant difference between the mean values of owner's education and business performance as reflected by a p-value of $0.001,<0.05$ at a $95 \%$ confidence level.

Applying the $p$-value rule that one should accept the proposition if the p-value is bigger than the alpha, $\left(\mathrm{H}_{0} 2\right)$ is therefore rejected.

This implies that education plays a role (has an effect) on business performance. This result is supported by literature as the GEM (2010) also reported that a healthy and educated workforce is important to a business's competitiveness and productivity. A significant statistical difference does exist between owner's educational qualification and "business performance". This result shows that the variable "owner's educational qualification" does play a significant role in business performance. The owner's higher qualification contributes to better business performance possibly because an educated person will first start with conducting research of the business he or she wants to establish before starting operations. Education is also an important factor in increasing skills level (GEM, 2011).

The researchers found it imperative to find out which level or levels of education had which effect on business performance.

This will be analysed further to find out which level of education is the reason for rejecting the hypothesis. 


\subsection{Further tests: Educational levels (strata) and business performance}

The result of the further analysis of the variable education of owner and business performance are shown in table 3 below. This is to test the hypotheses $\mathrm{H}_{0} 3$ which states that: there is a statistical significant difference between business performance and education strata grade 1 to 7 ( $\left.\mathrm{H}_{0} 3:-a\right)$ : grade 8 to 12 ( $\left.\mathrm{H}_{0} 3:-b\right)$; diploma $\left(\mathrm{H}_{0} 3:-\mathrm{c}\right)$; degree $\left(\mathrm{H}_{0} 3:-\mathrm{d}\right)$; and postgraduate ( $\left.\mathrm{H}_{0} 3:-\mathrm{e}\right)$.

We are trying to find out if we properly rejected the hypothesis, $\mathrm{H}_{0} 2$. Therefore we have to find out which educational level led us to reject the hypothesis or which levels are sources of rejection. Hypothesis $\mathrm{H}_{0} 3$ is tested using the Mann-Whitney's and the results are shown in Table 2

Table 2: The Mann-Whitney's test of the education and business performance

\begin{tabular}{|llc|}
\hline Education category & Education level & P-value \\
\hline Grade 1-7 & Grade 8-12 & 0.103 \\
& Diploma & 0.043 \\
& Degree & 0.002 \\
& Postgraduate & 0.018 \\
\hline Grade 8-12 & Diploma & 0.317 \\
& Degree & 0.001 \\
& Postgraduate & 0.123 \\
\hline Diploma & Degree & 0.015 \\
& Postgraduate & 0.287 \\
\hline
\end{tabular}

Confidence interval: 95\%a=0.05

The results show that there is a significant difference between category grade 1 to 7 and diploma (p-value of $0.043,<$ $\alpha=0.05$ ), degree ( $p$-value of $0.002,<\alpha=0.05$ ), postgraduate ( $p$-value of $0.018,<\alpha=0.05$ ), degree ( $p$-value of 0.001 and $0.015,<a=0.05)$. Applying the $p$-value rule that one should accept the proposition if the $p$-value is bigger than the alpha, hypothesis grade 1 to $7\left(\mathrm{H}_{0} 2:-a\right)$ and $\left(\mathrm{H}_{0} 2:-\mathrm{b}\right)$; diploma $\left(\mathrm{H}_{0} 2:-\mathrm{c}\right)$; degree $\left(\mathrm{H}_{0} 2:-\mathrm{d}\right)$ and postgraduate $\left(\mathrm{H}_{0} 2:-\mathrm{e}\right)$ are all accepted. Grade 1-7 and the degree have a significant difference at p-value of 0.002. Grade 8-12 and the degree have significant difference at $p$-value of 0.001 . In the last category, diploma and the degree have a significant difference at 0.015 . What the result mean is that there is a significant difference between category grade 1-7 and a degree but there is no difference between the first (grade 1-7) and second category ( grade 8-12). There is also a difference between category grade 8-12 and the degree. Therefore the more education one has, the better his/ her business is likely to perform. Education makes a difference in business performance. This means that the $\mathrm{H}_{0} 2$ was correctly rejected.

The findings are that a statistically significant variation does exist between the different education level strata as shown in table2 above.

The GEM (2011) reported in 2011 that South Africa had a significant increase in the rate for individuals, with some secondary levels of education, involved in entrepreneurial activity (46.7\%). South Africa's ranking with respect to primary education is dismal as shown in the 2010/2011 Global Competitiveness Report. The report indicated that a lack of basic education may limit business development by making it increasingly difficult for companies to move up the value chain and produce more sophisticated or value-intensive products. It is therefore of concern that South Africa ranked $125^{\text {th }}$ out of 139 countries with respect to the quality of its education. With respect to the quality of mathematics and science education, South Africa was even further down the ranking at $137^{\text {th }}$ (GEM, 2010). The lack of accessible research and development has been highlighted by national experts as an important factor constraining entrepreneurship in the country.

\section{Conclusion and Recommendation}

The study sought to determine if the demographic variables; owner's education and gender influence the dependent variable business performance. Hypotheses were designed to find out how the demographic variables education of owner and gender affect business performance.

The results show that there is a significant difference in performance, among the different educational levels. Those with higher levels of education, such as diplomas and degrees should be encouraged to take up entrepreneurship as career options since the businesses they would run tend to perform better. This would be good for the economy. In Europe, universities introduced entrepreneurship education to play a key role in the creation of new ventures (Sikalieh \& 
Otieno, 2011). Entrepreneurship education should equip students with relevant experience and help them develop selfconfidence. Therefore lack of these qualities, found to be the reasons for new graduates not engaging in entrepreneurship after graduation (Sikalieh \& Otieno, 2012).

This result shows that the variable "gender" does play a significant role in business performance. This implies that gender affects business performance. Studies by Cliff (1998), comparing the performance of male and female owned firms has consistently shown that businesses by women tend to be small than those headed by men, whether size, is measured by gross revenues, number of employees or profit level.

The study was limited to SMEs in Gauteng province and therefore the results may not be generalised to other regions or provinces where the structural make-up of entrepreneurs may be different. Secondly, all data was gathered at a specific time, thus the variables, responses and results may be limited to that point in time. The study is also based on SMEs and results may not apply to big businesses

Further research might establish which businesses (male/female) perform better than the other and the reasons why. Further study can also look other sectors other than retail and in other developing countries.

\section{References}

Akca, Y., Esen, S. \& Ozer, G.(2013). The effect of education on enterprise resource planning: Implementation success and perceived organisational performance. International Business Research. Vol.6, No. 5, 168-179.

Arenius, P. \& Minniti, M. (2004). Perceptual variables and nascent entrepreneurship. Small Business Economics, 24(3). $233-247$.

Bengtsson, O, Sanandaji, T. \& Johannesson, M. (2012). Do women have a less entrepreneurial personality? Research Institute of Industrial economics. Working paper No: 944, 1-31.

Cliff, J. (1998). Does one size fit all? Exploring the relationship between attitudes towards growth, gender and business size. Journal of Business Venturing, 13. 523-542.

Cooper, D.R. \& Schindler, P.S. (2008). Business research methods. 10th edition. Boston: McGraw-Hill Irwin.

Dimantopoulos, A. \& Schlegelmilch, B.B. (2002). Taking the fear out of data analysis. London, U K: Thomson Learning.

Global Entrepreneurship Monitor (GEM). (2009). 2009 Report on Higher Expectation Entrepreneurship from: www.gemconsortium.org (accessed on 3 June 2010).

Global Entrepreneurship Monitor (GEM). (2010). 2010 Report on Higher Expectation Entrepreneurship from:www.gemconsortium.org (accessed on 1 June 2011).

Global Entrepreneurship Monitor (GEM).(2011). 2011 Report on Higher Expectation Entrepreneurship from:www.gemconsortium.org (accessed on 1 June 2012).

Li, Y.H, Huang, J.W. \& Tsai, M.T. (2009). Entrepreneurial orientation and company performance: The role of knowledge creation process. Industrial Marketing Management 38(209):440-449.

Lumpkin, G.T. \& Dess, G.G. (2001). Linking two dimensions of entrepreneurial orientation to business performance: The moderating role of environment and industry life cycle. Journal of Business Venturing 16:429-451.

Urban, B. (2004). Understanding the moderating effect of culture and self-efficacy on entrepreneurial intentions. Doctoral thesis submitted at the University of Pretoria in April 2004.

McClelland, D.C. (1998). Identifying competencies with behavioural-event interview. Sage Journal of Psychological Science 9(5): pp331-339.

Mitchell, R., Smith, J.B., Morsem, E.A., Seawrignht, K., Perdo, A.M. \& McKenzie. B. (2002). Are entrepreneurial cognitions universal? Assessing entrepreneurial cognitions across cultures. Entrepreneurship Theory and Practice. Vol. 26, No 4, 9-32.

Morris, M, Schindehutte, M. \& Lesser, J. (2002). Ethnic entrepreneurship. Do values matters? New England Journal of Entrepreneurship, Fall 5 (2), 35-46.

Murphy, G.B., Trailer, J.W. \& Hill, R. (1996). Measuring performance in entrepreneurship research. Journal of Business Research. Vol. 36(1):15-23.

Quan, X. (2012). Prior experience, social network, and levels of entrepreneurial intentions. Management Research Review. Vol, (35), 945-957.

Rosa, P, Carter, S. \& Hamilton, D. (1996) Gender as a determinant of small business performance: Insight from British study. Small Business Economics 8, 463-478

Schumpeter, J.A. (1934). Theory of economic development. Cambridge, Mass: Harvard University Press.

Sikalieh D. \& Otieno H. (2011). Research Report submitted to the Institute of Social Ministry and Mission (ISMM), Tangaza College of the Catholic University of Eastern Africa. November 2011.

Takahashi, S.I.Y. (2009). Entrepreneurs as decisive human resources and business. Performance for the Lao SMEs. Chinese Business Review 8(7):29-47.

Van Scheers, M.L. \& Radipere, N.S. (2007). Why are so many managers not managing? African Journal of Business Management, (3) 85-91.

Wiklund, J. \& Shepherd, D. (2004). Knowledge-based resources, entrepreneurial orientation and performance of small and medium businesses. Strategic Management Journal 24:1307-1314. 